\title{
Mind, body, spirit: co-benefits for mental health from climate change adaptation and caring for country in remote Aboriginal Australian communities
}

\author{
Helen L. Berry ${ }^{\mathrm{A}, \mathrm{B}, \mathrm{J}}$, James R. A. Butler ${ }^{\mathrm{C}}$, \\ C. Paul Burgess ${ }^{\mathrm{D}}$, Ursula G. King ${ }^{\mathrm{B}}$, \\ Komla Tsey ${ }^{\mathrm{E}, \mathrm{F}}$, Yvonne L. Cadet-James ${ }^{\mathrm{E}, \mathrm{G}}$, \\ C. Wayne Rigby ${ }^{\mathrm{H}}$ and Beverley Raphael ${ }^{\mathrm{B}, \mathrm{I}}$ \\ ${ }^{\mathrm{A}}$ Faculty of Health, The University of Canberra \\ ${ }^{\mathrm{B}}$ College of Medicine, Biology and Environment, The Australian \\ National University \\ ${ }^{\mathrm{C}}$ CSIRO Sustainable Ecosystems and Climate Adaptation \\ Flagship, Brisbane \\ ${ }^{\mathrm{D}}$ Menzies School of Health Research, Charles Darwin University \\ ${ }^{\mathrm{E}}$ The Cairns Institute, James Cook University \\ ${ }^{\mathrm{F}}$ School of Education, James Cook University \\ ${ }^{\mathrm{G}}$ School of Indigenous Australian Studies, James Cook University \\ ${ }^{\mathrm{H}}$ Faculty of Nursing, Midwifery and Indigenous Health, \\ Charles Sturt University \\ ${ }^{\mathrm{I}}$ School of Medicine, University of Western Sydney \\ ${ }^{\mathrm{J}}$ Corresponding author.Email: Helen.Berry@canberra.edu.au
}

\begin{abstract}
The evident and unresolved health disparity between Aboriginal and other Australians is testament to a history of systematic disenfranchisement. Stigma, lack of appropriate services and the expense of delivering services in remote settings make it impossible to adequately address mental health needs, including suicide, solely using a mainstream medical approach. Nor do mainstream approaches accommodate the relationship between Aboriginal health and connectedness to land, whether traditional or new land, remote or metropolitan. This review describes how caring-for-country projects on traditional lands in remote locations may provide a novel way to achieve the linked goals of climate change adaptation with co-benefits for social and emotional wellbeing.
\end{abstract}

There are links between the natural environment, cultural identity and health, especially among the world's indigenous peoples (we refer to indigenous peoples globally and Aboriginal Australians locally). ${ }^{1}$ In Australia, the natural environment is threatened: the overwhelming weight of evidence suggests continuing and potentially catastrophic climate change, largely due to human actions. ${ }^{2-4}$ Exposure to climate-related adversities will increase, and the most vulnerable communities and regions will be worst affected. ${ }^{5}$ Reflecting a lack of research, policy and services for climate change and health in Australia, a Tri-Ministerial Press Release of 27 January 2009 on the health risks of climate change in Australia called for research to identify "who will be most vulnerable and the action governments, individuals and communities can take to reduce the risks'. ${ }^{6}$

This paper describes how caring-for-country projects may provide a novel way to achieve the linked goals of climate change adaptation and co-benefits for remote Aboriginal social and emotional wellbeing. We summarise what is known about the environmental and health benefits of caring for country (defined in Box 1), together with the relationship between social processes in communities and mental health, and then link these in a proposed conceptual framework that illustrates how climate change adaptation may deliver co-benefits for wellbeing.

The health disparity between Aboriginal and most other Australians is well documented, as is the importance for Aboriginal people of lifelong connectedness to healthy country. ${ }^{10,11}$ While we focus here on traditional lands, we acknowledge the importance for Aboriginal wellbeing of connectedness to new lands. Indeed, the last two centuries have seen people displaced from their traditional lands, ${ }^{12}$ with remnants of populations relocated to remote area townships. ${ }^{13}$ This movement has been associated with poor health outcomes for Aboriginal people ${ }^{14,15}$ and for lands and seas. In their present state, many of these lands cannot offer their traditional custodians the benefits of connectedness to healthy country. Climate change poses a new threat to these lands, through physical, ecological and sociocultural 


\section{Box 1. Caring for country: definition}

For Aboriginal peoples, 'country' encompasses an interdependent relationship between Aboriginal peoples and their ancestral lands and seas. ' 'Country is multi-dimensional - it consists of people, animals, plants, Dreamings, underground, earth, soils, minerals and waters, air ... People talk about country in the same way that they would talk about a person. ${ }^{8}$ 'Caring for country' means participation in inter-related activities on Aboriginal lands and seas with the objective of promoting ecological, spiritual and human health. It is also a community-driven movement towards long-term social, cultural, physical and sustainable economic development in rural and remote locations, contributing to the conservation of globally-valued environmental and cultural assets. ${ }^{9}$ Aboriginal landowners deliver a broad suite of environmental services, including:

- Border protection

- Quarantine

- Wild fire abatement and carbon sequestration

- Controlling invasive weeds and feral animals

- Conserving biodiversity

- Fisheries management

- Water resource management

- Sustainable commercial use of wildlife

- Cultural maintenance.

changes. ${ }^{16}$ Aboriginal and Torres Strait Islander people are particularly vulnerable: for example, many of the Torres Strait Islands' 7000 people live just 2 metres above sealevel. ${ }^{17}$ Land degradation disproportionately disadvantages those living closest to the land, ${ }^{18}$ especially Aboriginal Australians, who have and need a strong connection to land, ${ }^{10,19}$ and already live with endemic, historically-based, 'whole person, whole community' disadvantage. ${ }^{20,21}$ While we acknowledge the importance of Aboriginal connectedness to land, whether traditional or new, urban or remote, this paper focuses on rural and remote settings because Aboriginal people are over-represented here and disadvantage is even greater than it is in cities. ${ }^{22}$

Despite 'whole person, whole community' disadvantage, Aboriginal people have demonstrated formidable cultural resilience; a central tenet in maintaining wellbeing has been to preserve and evolve traditional knowledge from generation to generation. Community-initiated promotion and reintegration of this knowledge (to care for country) could assist in adapting to - and perhaps mitigating - adverse impacts of climate change. It could simultaneously support connectedness to healthy country; promote dignity, identity and self-determination; build community strength; offer opportunities for sustainable economic development and generate powerful co-benefits for social and emotional wellbeing, particularly where these activities are Aboriginal led.

\section{Aboriginal-led caring for country}

Although community approaches are known to be more effective than individually-based approaches in improving mental health practices in the face of rural drought, ${ }^{23,24}$ we do not yet know whether community-led caring-for-country projects could produce both benefits for country and personal empowerment (and its social and emotional co-benefits). However, there is growing interest in engaging rural and remote Aboriginal communities in these projects to build sustainable livelihoods. This is of interest because much of the world's biodiversity is found on indigenous traditional lands. ${ }^{19}$ By restoring connections to country through land and sea management activities, traditional ecological knowledge is applied and re-invigorated, resulting in documented improvements in social, cultural and physical health as well as the health of the landscape. This is referred to as 'Healthy Country, Healthy People'. ${ }^{13,25,26}$

Healthy Country, Healthy People research in Arnhem Land has involved measuring participation in six caring-forcountry activities and relating participation in these activities to prospective health indicators (Boxes 2 and 3). These studies demonstrated benefits for clinically-measured body mass index, ${ }^{13}$ waist circumference, blood pressure, diabetic status, albumin : creatinine ratio, glycosylated haemoglobin, high density lipoprotein, lipid ratio and five-year cardiovascular risk. ${ }^{25}$ Health screening also demonstrated that caring for country was associated with significantly lower levels of general psychological distress. ${ }^{25}$ In addition, greater physical activity (associated with caring-for-country projects) is linked to better mental health directly and because it improves physical health, itself strongly linked to mental health. ${ }^{27,28}$ These studies provide preliminary evidence for potential social and emotional wellbeing benefits.

As 20\% of Australia's land mass is Aboriginal estate, much of it of high conservation value, there is considerable potential for establishing livelihoods based on providing environmental stewardship, resulting in linked social, 


\section{Box 2. Case study: Healthy Country, Healthy People}

At the request of traditional landowners in central Arnhem Land, the Northern Territory, a transdisciplinary team of medical, ecological and social researchers investigated whether caring for country was associated with better health outcomes and better landscape health. A questionnaire measuring caring-for-country participation was developed and validated in the study population ${ }^{7}$ and associations with health outcomes were explored. ${ }^{29}$ Controlling for sociodemographic characteristics and health behaviours, greater participation was associated with significantly better health, including diet, physical activity, mental health and lowered risk of diabetes, kidney disease and cardiovascular disease; ${ }^{29}$ and landscape conservation outcomes were superior to those in surrounding areas where stewardship had been disrupted, potentially increasing the landscape's resilience to climate change. $^{30,31}$

\section{Box 3. Case study: Aboriginal Australians caring for country}

Climate change poses risks to Aboriginal peoples ${ }^{32}$ but also presents opportunities to invest in climate change mitigation projects. One example is the West Arnhem Land Fire Abatement project where Aboriginal landowners have reinstated landscape burning regimes to prevent late season wild fires, generating tradable savings in greenhouse gas emissions. ${ }^{33}$ Participation in caring for country-related programs seems to deliver significant health promotion, ${ }^{34}$ in addition to delivering globally significant conservation outcomes. ${ }^{26,35}$ Importantly, these initiatives reflect the wishes of Aboriginal landowners - to develop sustainable enterprises based on their continued association with ancestral lands and seas. ${ }^{36}$

'Our identity as human beings remains tied to our land... Destroy this relationship and you damage - sometimes irrevocably individual human beings and their health. ${ }^{37}$

cultural and biodiversity benefits. ${ }^{38}$ Despite the practical difficulties of translating this idea into practice, ${ }^{19}$ this opportunity is now recognised in the Commonwealth's Department of Environment, Water, Heritage and the Arts Caring for Our Country Business Plan. Funds are being made available to record and apply traditional ecological knowledge to protect biodiversity, while also aiming to build Aboriginal community capacity and partnerships. While this is evidently an empowerment approach, which (theoretically) ought to be beneficial for social and emotional wellbeing, these projects have not been considered in terms of such benefits.

Though there are as yet no programs addressing potential climate change impacts on Aboriginal health and wellbeing, government initiatives, including Caring for Our Country, have funded Aboriginal ranger programs to undertake land and sea management. These initiatives build on Aboriginal knowledge of local ecosystems and climatic patterns ${ }^{39}$ and provide a partial template for how caring for country activities might support climate change adaptation and improved health. Encouragingly, many communities are independently engaging partners to enhance their own opportunities to care for their country. Examples of activities include feral animal and weed control, habitat restoration, monitoring climate change and bush tucker harvesting. These projects are of particular interest because they have been initiated by the communities themselves, rather than by governments or researchers.

\section{Strong people in strong communities}

Cohort studies of the life-course dynamics of social and emotional wellbeing, together with research into community connectedness and mental health, might suggest a reason why caring for country is related to greater wellbeing. This body of research indicates that there are, respectively, two important features of those who are best placed to withstand long-term adversity. Such people tend to be 'competent selves', people who respect themselves, are goal directed and engage actively with their problems, ${ }^{40}$ and live in functional communities that can and do sustain them. ${ }^{41}$ These communities are often described as having high levels of social capital (see below) which is strongly linked to better mental health, ${ }^{42-44}$ including in Australia. ${ }^{45}$ Further, social capital may be even more important for Aboriginal Australians' wellbeing than it is for other Australians. ${ }^{46}$ Of considerable importance in the context of continuing adverse climate change, social capital might be the key mediator of the relationship between climate change and mental health. ${ }^{47}$

The notion of a unique relationship between social capital and wellbeing among Aboriginal Australians is consistent with a view that social capital is a meaningful concept (and related to health) in remote Aboriginal communities but that it has to be re-interpreted to make sense: its components (such as norms, networks and trust) are best understood in terms of relationships with and obligations to specific land, around which life is organised. For example, among the Yolngu people of the Northern Territory living 
in the homelands, norms are interpreted in terms of ways of perceiving and acting (mulkurr) that are directed by detailed knowledge of and respect for the footprints (djalkiri) - that is, the ecology - of their traditional lands; social networks (gurrutu) are place-specific knowledge of how entities such as individuals, groups, clans, totems, languages and ceremonies are related; and trust (maarr) is about powerfulness arising from collective identity and respect for the (land-related) responsibilities it confers. ${ }^{11}$ In Australia, it has long been acknowledged that, to reduce the current preventable burden of disease, we must address lack of control as one aspect of a broader experience of Aboriginal powerlessness. ${ }^{48,49}$ For Aboriginal people, this control and the responsibility that accompanies it are fundamental issues of trust.

Community control of resources and decision making have featured prominently in strategies to improve Aboriginal health. ${ }^{50-52}$ Yet these initiatives, which are focused directly on health, do not address the stigma that surrounds mental health ${ }^{53}$ or its social causation: ${ }^{54}$ direct approaches are not necessarily the only or the best way, and nor do they address the need for connectedness to country or the dual threats to country posed by displacement (and associated environmental degradation) and climate change. Indeed, Aboriginal leaders have noted that effective health promotion activities might well emerge from outside the health sector. ${ }^{55}$

The first cohort study of how social and emotional needs in indigenous communities might be approached outside health-focused approaches was conducted by psychiatrist Alexander Leighton. ${ }^{56}$ His stories of how a small indigenous rural 'slum' in Canada (the Road) became a connected, thriving and productive community ${ }^{57}$ provide a template for how natural resource management projects might help redress Aboriginal disadvantage and adapt to climate change. Through successfully completing indigenous-led projects apparently unrelated to health, residents of the Road became practised at cooperating spontaneously to solve problems and achieve collective goals. Over time, based on continuing learning and successes, residents became creative and entrepreneurial.

The achievements of the Yolngu people in establishing homelands reflect a similar story of how people who are determined, who work project by project and who act in a context of respect for their culture can, with initially minimal infrastructure support, build a happy, healthy and, ultimately, sustainable place to live. ${ }^{11}$ Caring-for-country projects could do likewise.

\section{Climate change, caring for country and wellbeing:} a conceptual framework

Figure 1 is a conceptual framework representing our proposed relationship between Aboriginal-initiated and led caring-for-country projects and social and emotional wellbeing in the context of adverse climate change. We anticipate that caring-for-country projects, initiated partly in response to climate change, would strengthen Aboriginalspecific social capital (arrow 'a') as a result of (i) caring for and reconnecting - or connecting more deeply - with traditional lands, and (ii) the community development-like activities required to undertake such projects. Increases in social capital would, in turn, be associated with improved social and emotional wellbeing (arrow 'b') creating positive feedback loops whereby better health would contribute to enhanced social capital and greater engagement with caring for country. We have cited evidence that caring for country is directly related to improved health (arrow 'c'), but it is not known why this is, or whether caring for country project outcomes would differ across climate zones and, thus, be generalisable. This proposition could be tested and considered in terms of climate zone-specific climate change scenarios. Given the significance of the Aboriginal health disparity and of the need to adapt to climate change, testing these propositions empirically is a research priority.

\section{Conclusions}

The evident and unresolved health disparity between Aboriginal and other Australians bears testament to a history of systematic disenfranchisement. ${ }^{16}$ Suicide rates and the prevalence of mental health problems, while difficult to quantify precisely, ${ }^{21}$ are of grave concern. Stigma, $^{53}$ lack of (culturally-appropriate) ${ }^{58}$ services $^{22}$ and the expense of delivering services in remote settings make it impossible to adequately address these health needs solely using a mainstream medical approach. ${ }^{18,47}$ Nor do mainstream approaches accommodate the relationship between Aboriginal health and connectedness to healthy traditional land. Caring-for-country projects, particularly when Aboriginal-initiated, may provide a way to achieve the linked goals of climate change adaptation with co-benefits for social and emotional wellbeing. However, it is not yet clear to what extent they may build social capacity, nor how such impacts may be manifested in different biocultural and climatic contexts. Culturallyengaged and community-focused scientific knowledge is needed in this emerging field. More important perhaps is the need to promote a more informed, insightful and respectful policy debate about the potential impacts of adverse climate change on Aboriginal health and its connectedness to land.

We propose that, especially in severely disadvantaged communities, ${ }^{59}$ most mental health problems are socially caused and must be socially solved; ${ }^{54}$ mainstream mental health services, essential though they are, cannot alone address social and emotional wellbeing. Caring-for-country projects offer an opportunity to address climate change adaption and social and emotional wellbeing together. 


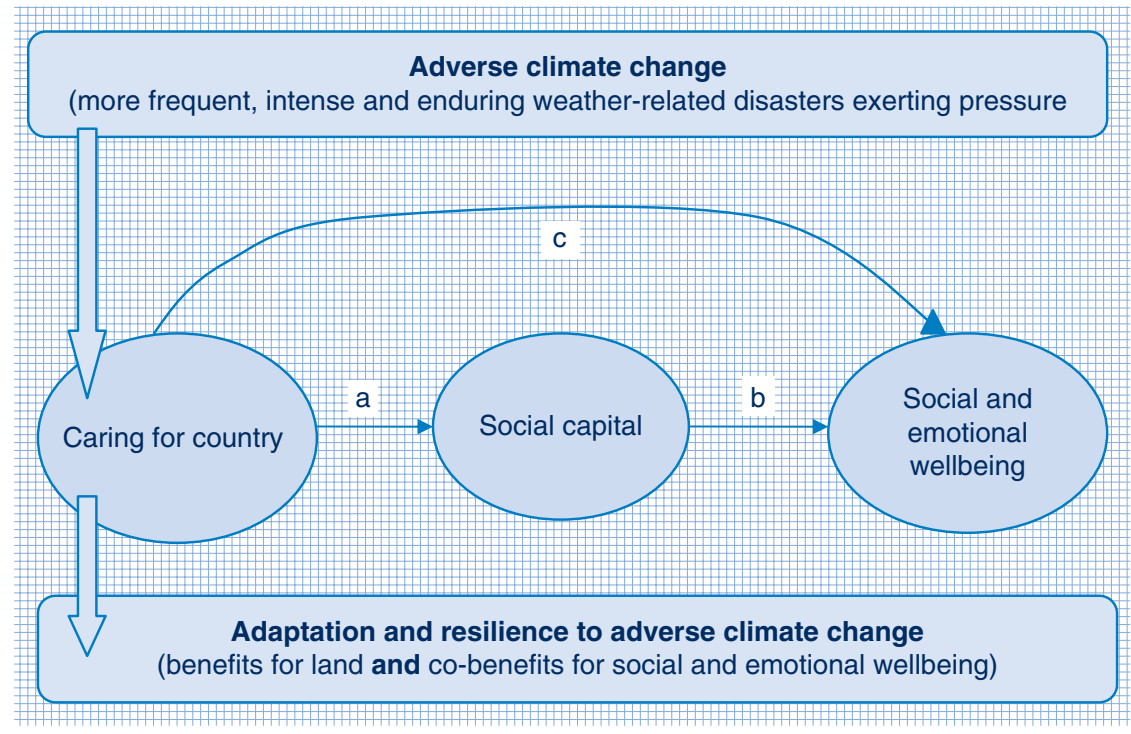

\begin{tabular}{|l} 
Key: \\
a direct relationship in which greater caring for country is hypothesised to \\
be causally related to higher levels of social capital \\
b direct relationship in which higher levels of social capital are related to \\
better social and emotional wellbeing in Aboriginal communities \\
c direct relationship in which greater caring for country is hypothesised to \\
be directly causally related to better social and emotional wellbeing in \\
Aboriginal communities net of its association with social capital.
\end{tabular}

Figure 1. Hypothesised conceptual framework linking caring-for-country projects directly and indirectly (through increased social capital) to improved wellbeing. Note: In this proposed framework, social capital partially mediates the relationship between caring for country and social and emotional wellbeing.

Such projects must be Aboriginal led, respecting a collective identity in which the group is always prior to the individual, ${ }^{11}$ and the imperative to work with (rather than 'do things to') communities in partnership with their leaders. ${ }^{55}$

\section{References}

1. King M, Smith A, Gracey M. Indigenous health part 2: The underlying causes of the health gap. Lancet 2009; 374: 76-85. doi:10.1016/S0140-6736(09)60827-8

2. Hulme M. IPCC: cherish it, tweak it or scrap it? Nature 2010; 463: 730-2. doi:10.1038/463730a

3. Smith JB, Schneider SH, Oppenheimer M, Yohee GW, Haref W, Mastrandreac MD et al. Assessing dangerous climate change through an update of the Intergovernmental Panel on Climate Change (IPCC) "reasons for concern." Proc Natl Acad Sci USA 2009; 106(11): 4133-7. doi:10.1073/pnas.0812355106

4. Rockström J, Steffen W, Noone K, Persson A, Chapin F, Lambin EF et al. A safe operating space for humanity. Nature 2009; 461: 472-5. doi:10.1038/461472a

5. McMichael AJ, Friel S, Nyong A, Corvalan C. Global environmental change and health: Impacts, inequalities, and the health sector. BMJ 2008; 336: 191-4. doi:10.1136/bmj.39392. 473727.AD
6. Tri-Ministerial Press Release. $\$ 10$ Million for research into health and climate change. Canberra: Commonwealth Government of Australia; 2009.

7. Burgess C, Berry H, Gunthorpe W, Bailie R. Development and preliminary validation of the 'Caring for Country' questionnaire: measurement of an Indigenous Australian health determinant. BMC Int J Equity Health 2008; 7(1): 26. doi:10.1186/1475-9276-7-26

8. Rose D. Nourishing terrains: Australian Aboriginal views of landscape and wilderness. Australian Heritage Commission, Commonwealth of Australia; 1996.

9. Morrison J. Caring for Country. In: Altman J, Hinkson M, editors. Coercive reconciliation stabilise, normalise, exit. Aboriginal Australia Arena Publications Association; 2007: 249-61.

10. Anderson P. Priorities in Aboriginal Health. In: Robinson G, editor. Aboriginal Health: social and cultural transitions. Darwin: NTU Press; 1995.

11. Christie M, Greatorex J. Yolngu life in the Northern Territory of Australia: the significance of community social capital. Asia Pac J Public Admin 2004; 26(1): 55-69.

12. Morley B, Pirkis J, Naccarella L, Kohn F, Blashki G, Burgess P. Improving access to and outcomes from mental health care in rural Australia. Aust J Rural Health 2007; 15: 304-12. doi:10.1111/j.1440-1584.2007.00905.x 
13. Burgess CP, Berry HL, Gunthorpe W, Baillie R. Development and preliminary validation of the 'Caring for Country' questionnaire: measurement of an Indigenous Australian health determinant. Int J Equity Health 2008; 7: 26. doi:10.1186/ 1475-9276-7-26

14. Scrimgeour D. Town or country: which is best for Australia's Indigenous peoples? Med J Aust 2007; 186: 532-3.

15. McDermott R, O’Dea K, Rowley K, Knight S, Burgess CP. Beneficial impact of the Homelands Movement on health outcomes in central Australian Aborigines. Aust NZJ Public Health 1998; 22(6): 653-8. doi:10.1111/j.1467-842X.1998.tb01464.x

16. Hunter E. 'Radical hope' and rain: climate change and the mental health of Indigenous residents of northern Australia. Australas Psychiatry 2009; 17(6): 445-52. doi:10.1080/10398560903062927

17. Green D, Alexander L, Mclnnes K, Church J, Nicholls N, White N. An assessment of climate change impacts and adaptation for the Torres Strait Islands, Australia. Clim Change 2010; 100(2). doi:10.1007/s10584-009-9756-2

18. Berry HL, Kelly BJ, Hanigan IC, Coates JH, McMichael AJ, Welsh JA et al. Rural Mental Health Impacts of Climate Change. Commissioned report for the Garnaut Climate Change Review. Canberra: The Australian National University; 2008.

19. Green D, Raygorodetsky G. Indigenous knowledge of a changing climate. Clim Change 2010; 100(2): 239-42. doi:10.1007/s10584-010-9804-y

20. Centre for Rural and Remote Mental Health Queensland. Who we are and what we do. In: Berry HL, Bowers J, editors. Strategic Plan 2008-2013. Cairns, Queensland: CRRMHQ; 2008.

21. Hunter E. Disadvantage and discontent: A review of issues relevant to the mental health of rural and remote Indigenous Australians. Aust J Rural Health 2007; 15: 88-93. doi:10.1111/ j.1440-1584.2007.00869.x

22. Smith KB, Humphreys JS, Wilson MGA. Addressing the health disadvantage of rural populations: How does epidemiological evidence inform rural health policies and research? Aust J Rural Health 2008; 16(2): 56-66. doi:10.1111/j.1440-1584.2008. 00953.x

23. Alston M. Social capital in rural Australia. Rural Soc 2002; 12(2): 93-104.

24. Stehlik D. Australian drought as lived experience: Social and community impacts. In: Botterill L, Fisher M, editors. Beyond Drought: People, Policy and Perspectives. Melbourne: CSIRO Publishing; 2003.

25. Burgess CP, Johnston F, Berry HL, McDonnell J, Yibarbuk D, Gunabarra $\mathrm{C}$ et al. Healthy country, healthy people: the relationship between Indigenous health status and "caring for country". Med J Aust 2009; 190(10): 567-72.

26. Garnett S, Sithole B, Whitehead P, Burgess C, Johnston F, Lea T. Healthy Country, Healthy People: Policy Implications of Links between Indigenous Human Health and Environmental Condition in Tropical Australia. Aust J Pub Admin 2009; 68(1): 53-66. doi:10.1111/j.1467-8500.2008.00609.x

27. Crone D. Physical activity and mental health. A Life in the Day 2003; 7(2): 23-8.

28. Herrman H. The need for mental health promotion. Aust N ZJ Psychiatry 2001; 35(6): 709-15. doi:10.1046/j.1440-1614.2001. 00947.x
29. Burgess C, Johnston F, Berry H, McDonnell J, Yibarbuk D, Gunabarra $\mathrm{C}$ et al. Healthy Country Healthy People: the relationship between Indigenous health status and "caring for country.' Med J Aust 2009; 190(10): 567-72.

30. Franklin D, Petty A, Williamson G, Brook B, Bowman D. Monitoring Contrasting Land Management in the Savanna Landscapes of Northern Australia. Environ Manage 2008; 41(4): 501-15. doi:10.1007/s00267-007-9006-1

31. Garnett S, Sithole B. NTU07 - Sustainable northern landscapes and the nexus with Indigenous health: Healthy Country Healthy People. Canberra. Available at: http://lwa.gov.au/files/products/ social-and-institutional-research-program/pn20681/pn20681. pdf (Accessed 7 June 2010.)

32. Green D, King U, Morrison J. Disproportionate burdens: the multidimensional impacts of climate change on the health of Indigenous Australians. Med J Aust 2009; 190(1): 4-5.

33. Putnis A, Josif P, Woodward E. Healthy Country, Healthy People: supporting Indigenous engagement in the sustainable management of Northern Territory land and seas: a strategic framework. Darwin: CSIRO. Available at: http://www.csiro.au/ resources/HealthyCountryHealthyPeopleReport.html (Accessed 7 June 2010.)

34. Burgess C, Johnston F, Bowman D, Whitehead P. Healthy Country: Healthy People? Exploring the health benefits of Indigenous natural resource management. Aust N Z J Public Health 2005; 29(2): 117-22. doi:10.1111/j.1467-842X.2005. tb00060.x

35. Campbell D, Davies J, Wakerman J. Realising economies in the joint supply of health and environmental services in Aboriginal Central Australia. Alice Springs: Desert Knowledge CRC; 2007.

36. Dodson P, Lane P, Suggit D, Birrel V. Our home, our homeland: Community Engagement Report. Available at: http://www. workingfuture.nt.gov.au/download/Community_Engagement_ Report.pdf (Accessed 7 June 2010.)

37. Anderson P, editor. Priorities in Aboriginal Health. Aboriginal Health: Social and cultural transitions; 29-31 September; Northern Territory University Darwin. Darwin: NTU Press; 1995.

38. Altman JC, Buchanan G, Larsen L. The environmental significance of the indigenous estate: natural resource management as economic development in remote Australia. Canberra: The Australian National University; 2007. Contract No.: CAEPR Discussion Paper No. 286/2007.

39. Green D, Billy J, Tapim A. Indigenous Australians' knowledge of weather and climate. Clim Change 2010; 100(2): 337-54. doi:10.1007/s10584-010-9803-z

40. Elder GH. Historical change in life patterns and personality. Life Span Devel Behavior 1979; 2: 117-59.

41. Almedom AM. Social capital and mental health: An interdisciplinary review of primary evidence. Soc Sci Med 2005; 61(5): 943-64. doi:10.1016/j.socscimed.2004.12.025

42. Berkman LF, Melchior M, Chastang J-F, Niedhammer I, Leclerc A, Goldberg M. Social Integration and Mortality: A Prospective Study of French Employees of Electricity of France-Gas of France: The GAZEL Cohort. Am J Epidemiol 2004; 159(2): 167-74. doi:10.1093/aje/kwh020

43. Prince M, Harwood R, Thomas A, Mann A. A prospective population-based cohort study of the effects of disablement 
and social milieu on the onset and maintenance of late-life depression. The Gospel Oak Project VII. Psychol Med 2009; 28: 337-50. doi:10.1017/S0033291797006478

44. Riise T, Lund A. Prognostic factors in major depression: A longterm follow-up study of 323 patients. J Affect Disord 2001; 65(3): 297-306. doi:10.1016/S0165-0327(00)00260-3

45. Berry HL, Welsh JA. Social capital and health in Australia: An overview from the Household Income and Labour Dynamics in Australia Survey. Soc Sci Med 2010; 70: 588-96. doi:10.1016/ j.socscimed.2009.10.012

46. Berry HL. Social capital and mental health among Indigenous Australians, New Australians and Other Australians living in a coastal region. Aust e-J Advance. Ment Health (Lond) 2009; 8(2): 142-54.

47. Berry HL, Bowen K, Kjellstrom T. Climate change and mental health: A causal pathways framework. Int J Public Health 2010; 55(2): 123-32. doi:10.1007/s00038-009-0112-0

48. National Aboriginal Health Strategy Working Party. A national Aboriginal health strategy. Canberra: Commonwealth Government of Australia; 1989.

49. Tsey K, Every A. Evaluating Aboriginal empowerment programs: The case of Family WellBeing. Aust N Z J Public Health 2000; 24(5): 509-14. doi:10.1111/j.1467-842X.2000.tb00501.x

50. Bartlett B, Boffa J. Aboriginal Community Controlled Comprehensive Primary Health Care: The Central Australian Aboriginal Congress. Aust J Prim Health 2001; 7(3): 74-82. doi:10.1071/PY01050

51. Shannon C, Carson A, Atkinson RC. The manager. Med J Aust 2006; 184(10): 530-1.
52. Social justice information sheet 2003. Available from: http:// www.humanrights.gov.au/social_justice/info_sheet.html (Accessed 24 February 2010.)

53. Sartorius N. Stigma and mental health. Lancet 2007; 370(9590): 810-1. doi:10.1016/S0140-6736(07)61245-8

54. Fryer D. For better or worse? Interventions and mental health consequences of unemployment. Int Arch Occup Environ Health 1999; 72: S34-7.

55. National Health and Medical Research Council. Report to the Aboriginal and Torres Strait Islander Research Agenda Working Group (RAWG): Final report of community consultations on the RAWG road map. Canberra: NHMRC; 2002.

56. Leighton AH. Poverty and social change. Sci Am 1965; 212(5): 21-7. doi:10.1038/scientificamerican0565-21

57. Berry HL. Pearl in the oyster: Climate change as a mental health opportunity. Australas Psychiatry 2009; 17(6): 453-6. doi:10.1080/10398560903045328

58. National Aboriginal Community Controlled Health Organisation. Recommendations from National Aboriginal Community Controlled Health Organisation's Submission to the Primary Health Care Strategy Taskforce: Towards a National Primary Health Care Strategy: Fulfilling Aboriginal People's Aspirations to Close the Gap. Canberra: 2009.

59. Berry HL, Butterworth P, Caldwell TM, Rodgers B. Contemporary Australian archetypes: different types of people, different needs. Department of Families, Housing, Community Services and Indigenous Affairs. Canberra: Commonwealth Government; 2008. 